\title{
INVESTIGATION ON CORRODED HSS TUBULAR MEMBERS UNDER COMPRESSION STRENGTHENED WITH CFRP COMPOSITES
}

\author{
M.C. SUNDARRAJA ${ }^{1}$, P. SRIRAM ${ }^{2}$
}

\begin{abstract}
The main objective of this investigation is to assess the feasibility of strengthening of corroded (damaged) square hollow steel tubular sections subjected to compression and to develop or predict the suitable wrapping scheme of fibre reinforced polymer (FRP) to enhance the structural behaviour of it. For this study, compact mild steel tubes were used with the main variable being FRP characteristics. Carbon fibre reinforced polymer (CFRP) fabrics was used as horizontal strips (lateral ties) with other parameters such as the number of layers and spacing of strips. Among fourteen specimens, six were externally bonded by CFRP strips having a constant width of $50 \mathrm{~mm}$ with a spacing of $20 \mathrm{~mm}$ and the remaining six were externally bonded by CFRP strips having a constant width of $70 \mathrm{~mm}$ with a spacing of $20 \mathrm{~mm}$, two columns were unbonded. Experiments were undertaken until the failure of columns to fully understand the influence of FRP characteristics on the compressive behaviour of the square sections including their failure modes, axial stress-strain behaviour, enhancement in the load carrying capapcity, and effect of distribution of CFRP layers. Finally, the behaviour of externally bonded hollow tubular sections was compared with one another and also with the control specimens. Evaluation of the results will lead to optimum CFRP jacketing/ wrapping arrangements for the steel tubes considered here.
\end{abstract}

Keywords: HSS tubes, CFRP fabrics, strengthening, axial compression, externally bonded

\section{INTRODUCTION}

The hollow steel tubular (HSS) sections possess excellent structural and earthquake-resistant properties such as high strength and high ductility, and have gained increasing popularity in buildings, bridges and other structural applications as either onshore or offshore structures [1]. But they are exposed to deterioration, fire and corrosion due to severe environmental conditions or to the development of fatigue cracks when the structure is subjected to cyclic loads. Traditionally, the most common method to repair and/or rehabilitate a steel structure has been by welding additional steel plates. This not

${ }^{1}$ Faculty of Civil Engineering, Thiagarajar College of Engineering, Madurai, Tamilnadu, INDIA, e-mail-mcsciv@tce.edu

2 Thiagarajar College of Engineering, Madurai, Tamilnadu, INDIA, e-mail - sriram_civil@yahoo. co.in. Address for Correspondence:-mcsciv@tce.edu 
only adds weight to the structure, but the heat involved in welding can affect the stress distribution and may be critical for structures exposed to fatigue loads. In addition, steel plates would be exposed to corrosion damage and frequently this repairing method requires the use of scaffolding and heavy machinery as well as long periods of service interruption. In contrast, rehabilitation methods using fibre reinforced polymer (FRP) composites do not exhibit any of these drawbacks. The advantages of FRP over steel plates are the low weight of the bonded material, easy applicability and the capacity to cover areas with limited access, where the use of traditional techniques would be impractical [1]. High stiffness fibres, such as carbon fibres, can effectively enhance the structural properties of steel structures; additionally, composites could also enhance the fatigue life of steel structures. The use of FRP technology to increase the strength of tubular steel structures (retrofitting) in both offshore and onshore applications will bring considerable benefits to the industry. However, there has been limited research in this area. In an investigation [2], for tubular steel sections, butt-welded, very high strength circular steel tubes (VHS) reinforced with unidirectional CFRP sheets were tested under tensile load. The results showed that the strength increase varied from $25 \%$ to $76 \%$, which proved that CFRP wrapping is an effective method to strengthen VHS tubes. Shaat and Fam [3] found that transverse CFRP layers are effective in confining the outward local buckling of short columns and that the load capacity increased by $18 \%$ for short columns and $13 \%$ to $23 \%$ for long columns. They recommended that further studies would be conducted on thin-walled sections with larger width-to-thickness ratios, where local buckling could be more critical for short columns. Shaat and Fam [4] also developed an analytical model for slender steel hollow section columns strengthened with CFRP sheets. A limiting strain of $0.13 \%$ was adopted in the model for the CFRP in compression. They recommended that further research is needed to examine the applicability of this value to other types of CFRP, or when CFRP is bonded to steel hollow sections of different sizes.

Zhao et al. [5] carried out tests on CFRP strengthened concrete-filled steel hollow section short columns. The increase in load carrying capacity was found to be 5-22\% and $20-44 \%$ when one and two layers of CFRP were applied. The load capacity enhancement increased with increasing diameter-to-thickness ratio. Tae et al. [6] also carried out tests on concrete-filled steel hollow short columns strengthened by CFRP. They found that more research is needed to investigate the effect of number of layers, the fibre orientation, and the gap between CFRP and steel on the behaviour and strength.

Seica et al. [1] investigated the flexural performance of compact circular hollow sections (CHS) beams strengthened by CFRP sheets (two layers in the longitudinal direction and one in the transverse direction). In addition to strength increase, they found that a class 2 section wrapped with CFRP can reach a moment capacity above the plastic moment capacity, with increased ductility and rotation capacity. However, the number of tests was not sufficient to show whether a class 2 section can be upgraded through wrapping CFRP sheets to a class 1 section. Haedir et al. [7] conducted tests on 
class 4 CHS beams strengthened by CFRP sheets. They showed that a class 4 section can be upgraded to a class 2 section if CFRP strengthening is applied in both longitudinal and hoop directions. It was found that the hoop layers played a more important role in restraining or delaying the local buckling which is often in the form of an ovalisation for CHS. The longitudinal layers played a more important role in increasing the moment capacity, due to the contribution of CFRP in the tension zones. They concluded that more tests are required to derive an optimal combination of these factors of fibre orientation, number of layers and sequence in applying CFRP layers and research is also needed to investigate the behaviour of rectangular hollow sections and other classes of CHS strengthened by CFRP they added.

Bambach et al. [8] studied the axial compressive behaviour of CFRP strengthened cold-formed square hollow sections using experiments. They showed that the application of CFRP delayed local buckling, and that the elastic buckling strength of slender sections is increased by up to 4 times. However they only considered two layouts of CFRP. More tests are required to derive an optimal combination of fibre orientation, number of layers and sequence in applying CFRP layers. In summary, a thorough literature review has shown that the strength improvements of hollow structural steel tubes using CFRP sheets are feasible. To date, limited research has been undertaken on hollow square and rectangular steel tubular members although they are increasingly used in off-shore and on-shore applications. This research is aimed to assess the feasibility of strengthening of artificially corroded hollow tubular steel members subjected to compression and to develop an adequate repair method for in-air applications using FRP technology.

\section{Materials}

\subsection{Steel Tube}

The square hollow steel tube confirming to IS 4923-1997 and IS 1161-1998 having a dimension of $91.5 \mathrm{~mm} \times 91.5 \mathrm{~mm}$ was used in this study. The thickness and height of the square hollow steel tube are $3.6 \mathrm{~mm}$ and $600 \mathrm{~mm}$ respectively. The yield strength provided by the manufacturer is $250 \mathrm{~N} / \mathrm{mm}^{2}$. The hollow specimens are shown in Figure 1. 


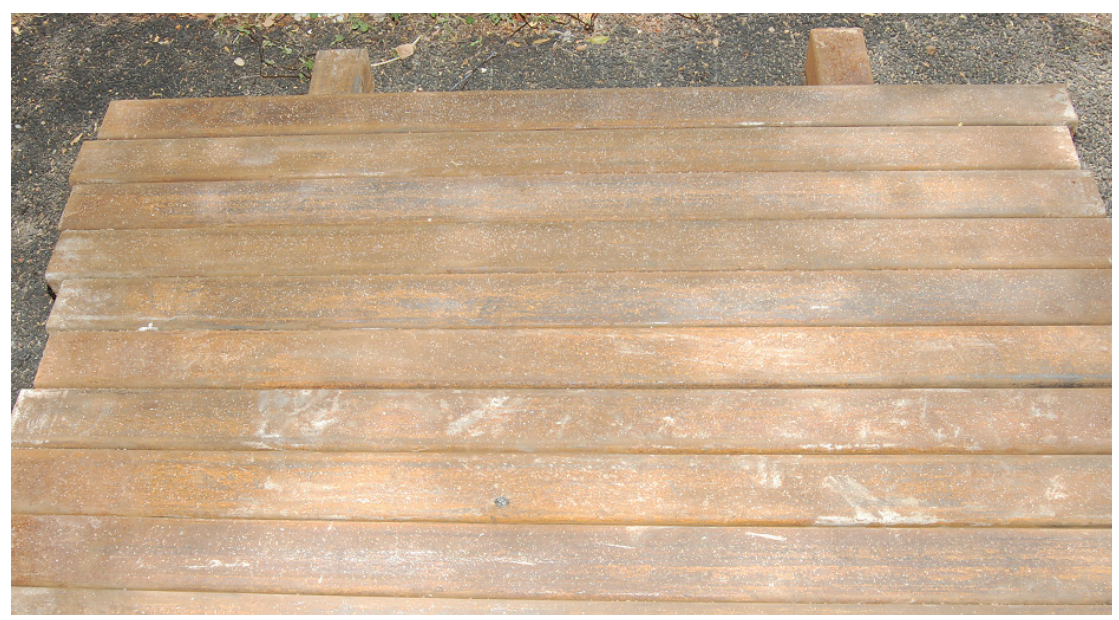

Fig. 1. Hollow steel tubular sections

\subsection{CARbon Fibre}

The unidirectional carbon fibre called MBrace 240, fabricated by BASF India Inc was used in this study. It is a low modulus CFRP fibre having modulus of elasticity of $240 \mathrm{kN} / \mathrm{mm}^{2}$ and the tensile strength is $3800 \mathrm{~N} / \mathrm{mm}^{2}$. The thickness and width of the fibre are $0.234 \mathrm{~mm}$ and $600 \mathrm{~mm}$ respectively. It is fabric type and can be tailored into any desired shape. The properties of CFRP fabrics supplied by the manufacturer are summarised in Table 1.

Table 1

Properties of carbon fibre reinforced polymer

\begin{tabular}{|c|c|c|}
\hline S.No & Properties of CFRP & Value \\
\hline 1. & Modulus of Elasticity & $240 \mathrm{kN} / \mathrm{mm}^{2}$ \\
\hline 2. & Tensile Strength & $3800 \mathrm{~N} / \mathrm{mm}^{2}$ \\
\hline 3. & Weight of C fibre & $400 \mathrm{~g} / \mathrm{m}^{2}$ \\
\hline 4. & Density & $1.7 \mathrm{~g} / \mathrm{cm}^{2}$ \\
\hline 5. & Thickness of static design weight / density & $0.234 \mathrm{~mm}$ \\
\hline
\end{tabular}

\subsection{Adhesive}

The MBrace saturant supplied by BASF India Inc was used in this study to get the good bonding between steel tube and carbon fibre. It is a two part systems, a resin and a hardener and the mixing ratio was 100:40 $(\mathrm{B}: \mathrm{H})$. The properties of saturant supplied by the manufactures are given in Table 2 . 
Table 2

Properties of MBrace saturant

\begin{tabular}{|c|c|c|}
\hline S.No. & Properties & Value \\
\hline 1. & Mixing ratio, by weight & 100(Base): 40(Hardener) \\
\hline 2. & Mixed Density (kg/litre) & $1.13 \pm 0.03$ \\
\hline 3. & Mixed Viscosity $\left(\right.$ at $\left.25^{\circ} \mathrm{C}\right)$ & $4000 \pm 500$ \\
\hline 4. & Setting time & $<3$ hrs at $25^{\circ} \mathrm{C}$ \\
\hline 5. & Full cure & 7 Days \\
\hline
\end{tabular}

\section{EXPERIMENTAL PROGRAMME}

The main objective of this investigation is to study the comparative behavior of corroded HSS tubular sections strengthened with unidirectional CFRP fabrics with different wrapping schemes. A series of 14 specimens were tested in this study. The objective is to evaluate the failure modes, ultimate load carrying capacity, and axial stress-strain behavior.

\subsection{Specimen Fabrication}

The $600 \mathrm{~mm}$ height square hollow tubes were cut from $6 \mathrm{~m}$ length hollow tubes. To get the flat surface, both ends of the steel tube were surfaced by the surface grinding machine. Inside portion of the hollow steel tubes were made corrosive resistant by the provision of a thin layer of molten wax. To ensure full utilization of CFRP material, surface preparation of the steel must be undertaken. Hence, the surface of the corroded specimens was cleaned with acetone solvent to ensure good bonding strength, before the strengthening is initiated.

\subsection{Internal Resistance to Corrosion}

Internal resistance to corrosion is achieved by covering the internal surface with a thin layer of molten wax which was poured inside to avoid any internal changes that may occur inside the specimen. Before that the debris and contaminants inside the specimens were thoroughly wire brushed to have a smooth surface for waxing.

\subsection{Artificial Corrosion of Specimens}

The two main types of artificial corrosion methods for the steel are by electrical charging and creating acidic environment. In electrical charging method, time consumption is more since the specimens have to be electrically degraded one after the other. Secondly, creating acidic environment is a cheap and an efficient artificial corrosion method. In this research, corrosion mechanism is by creating acidic environment. This 
was achieved by the proportion of adding 70 grams of sodium chloride $(\mathrm{NaCl})$ salt and $100 \mathrm{ml}$ of acidic acid for 1 litre of ordinary tap water. This solution is filled little above the height of the complete immersion of specimens in the circular artificial corrosion tank. And the corrosion period is based on the weight reduction mechanism. In order to increase the corrosion rate the hollow steel tube specimens be placed in open environment and corrosion tank for alternative days. Then the weight loss for hollow steel tube specimens was measured constantly in a cycle of 5 days and after achieved the required weight loss of the specimens, the corrosion mechanism is stopped and the total corrosion period is limited to 25 days. Specimens before corrosion and after corrosion are shown in Figures 2 and 3. The observations during corrosion process are given in Table 3.

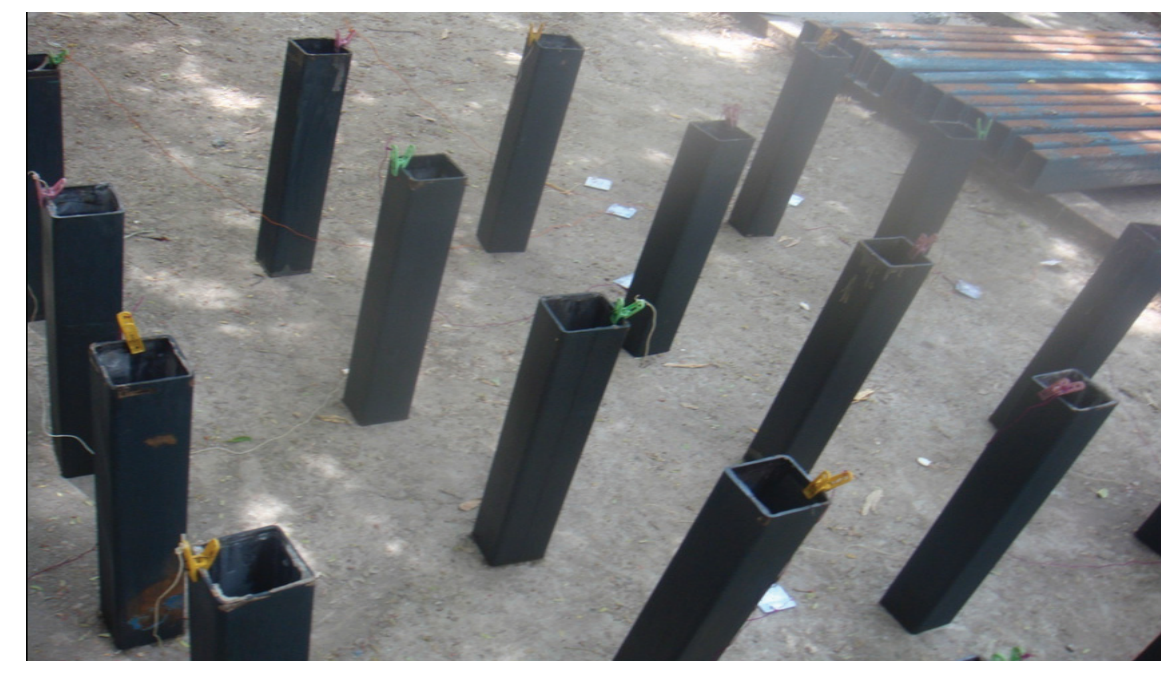

Fig. 2. Specimens before corrosion

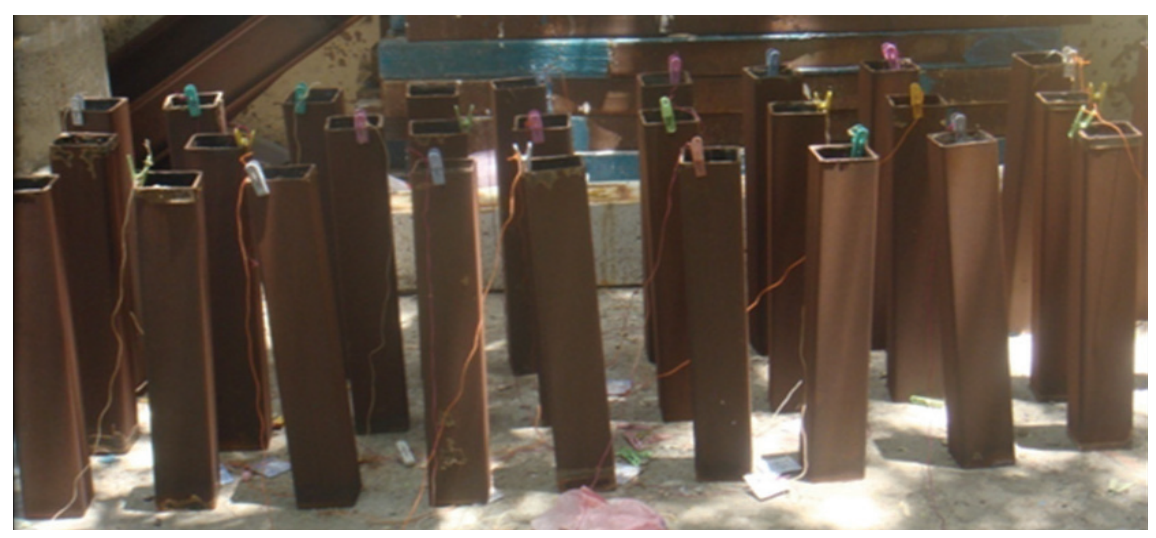

Fig. 3. Specimens after corrosion 
Table 3

Observations during corrosion process

\begin{tabular}{|c|c|c|c|c|c|c|c|c|}
\hline \multirow{2}{*}{$\begin{array}{c}\text { S. } \\
\text { No }\end{array}$} & $\begin{array}{c}\text { Designation of } \\
\text { columns }\end{array}$ & $\begin{array}{c}\text { Initial } \\
\text { weight in } \\
\text { kg }\end{array}$ & $\begin{array}{c}\text { Loss of } \\
\text { Weight } \\
\text { after } \\
\mathbf{5} \text { days }\end{array}$ & $\begin{array}{c}\text { Loss of } \\
\text { Weight } \\
\text { after } \\
\mathbf{1 0} \text { days }\end{array}$ & $\begin{array}{c}\text { Loss of } \\
\text { Weight } \\
\text { after } \\
\mathbf{1 5} \text { days }\end{array}$ & $\begin{array}{c}\text { Loss of } \\
\text { Weight } \\
\text { after } \\
\mathbf{2 0} \text { days }\end{array}$ & $\begin{array}{c}\text { Loss of } \\
\text { Weight } \\
\text { after } \\
\mathbf{2 5} \text { days }\end{array}$ & $\begin{array}{c}\text { Total } \\
\text { loss of } \\
\text { weight } \\
\text { kg }\end{array}$ \\
\hline 1 & CC1 & 5.699 & 5.647 & 5.631 & 5.62 & 5.594 & 5.551 & 0.148 \\
\hline 2 & CC2 & 5.701 & 5.649 & 5.68 & 5.564 & 5.547 & 5.531 & 0.17 \\
\hline 3 & HS-50-20-T1(1) & 5.724 & 5.659 & 5.642 & 5.637 & 5.604 & 5.588 & 0.136 \\
\hline 4 & HS-50-20-T1(2) & 5.694 & 5.634 & 5.614 & 5.605 & 5.589 & 5.555 & 0.139 \\
\hline 5 & HS-50-20-T2(1) & 5.717 & 5.671 & 5.605 & 5.601 & 5.583 & 5.554 & 0.163 \\
\hline 6 & HS-50-20-T2(2) & 5.668 & 5.613 & 5.578 & 5.579 & 5.551 & 5.533 & 0.135 \\
\hline 7 & HS-50-20-T3(1) & 5.699 & 5.643 & 5.635 & 5.644 & 5.609 & 5.591 & 0.108 \\
\hline 8 & HS-50-20-T3(2) & 5.768 & 5.714 & 5.695 & 5.701 & 5.694 & 5.649 & 0.119 \\
\hline 9 & HS-70-20-T1(1) & 5.712 & 5.666 & 5.627 & 5.632 & 5.693 & 5.568 & 0.144 \\
\hline 10 & HS-70-20-T1(2) & 5.672 & 5.676 & 5.603 & 5.595 & 5.568 & 5.543 & 0.129 \\
\hline 11 & HS-70-20-T2(1) & 5.746 & 5.698 & 5.673 & 5.67 & 5.647 & 5.628 & 0.118 \\
\hline 12 & HS-70-20-T2(2) & 5.707 & 5.653 & 5.632 & 5.6 & 5.599 & 5.552 & 0.155 \\
\hline 13 & HS-70-20-T3(1) & 5.806 & 5.738 & 5.723 & 5.718 & 5.701 & 5.694 & 0.112 \\
\hline 14 & HS-70-20-T3(2) & 5.633 & 5.568 & 5.587 & 5.59 & 5.571 & 5.545 & 0.088 \\
\hline
\end{tabular}

\subsection{Description of Specimens}

Among fourteen specimens, six were externally bonded by CFRP strips having a constant width of $50 \mathrm{~mm}$ with the spacing of $20 \mathrm{~mm}$. The size and height of the column specimens used were $91.5 \times 91.5 \times 3.6 \mathrm{~mm}$ and $600 \mathrm{~mm}$ respectively. To identify the specimens easily, the columns were designated with the names such as HS-50-20-T1, HS-50-20-T2, HS-50-20-T3, HS-70-20-T1, HS-70-20-T2 and HS-70-20-T3. For example, the specimen HS-50-20-T3 specifies that it was strengthened by three (3) layers of $50 \mathrm{~mm}$ width horizontal strip (HS) of CFRP fabrics in transverse direction (T) with the spacing of $20 \mathrm{~mm}$.

\subsection{Bonding of FRP on Steel Specimens}

The surface was thoroughly wiped off with application of acetone and the steel surface was prepared to the required standard and the saturant was mixed in accordance with the manufacturer's instructions. The base was added first and stirred followed by the 
hardener and it was mixed well slowly for at least 3 minutes before use. Mixing was carried out in a glass container and was continued until the mixture was in a uniform colour and then applied to the steel surface. A first coat of fully mixed MBrace saturant was applied using brush. For all the specimens, one layer of GFRP mat was laid over the steel surface to prevent the risk of galvanic action between the steel and the carbon fibre. Enough pressure using roller was applied to press out the excessive epoxy resin and trapped air pockets. The CFRP sheets are laid down in the similar manner over the GFRP layer and the epoxy resin comes out as the sheets get pressed with the help of rollers. This operation was carried out at room temperature before testing. The bonding of CFRP sheets are shown in Figure 4.

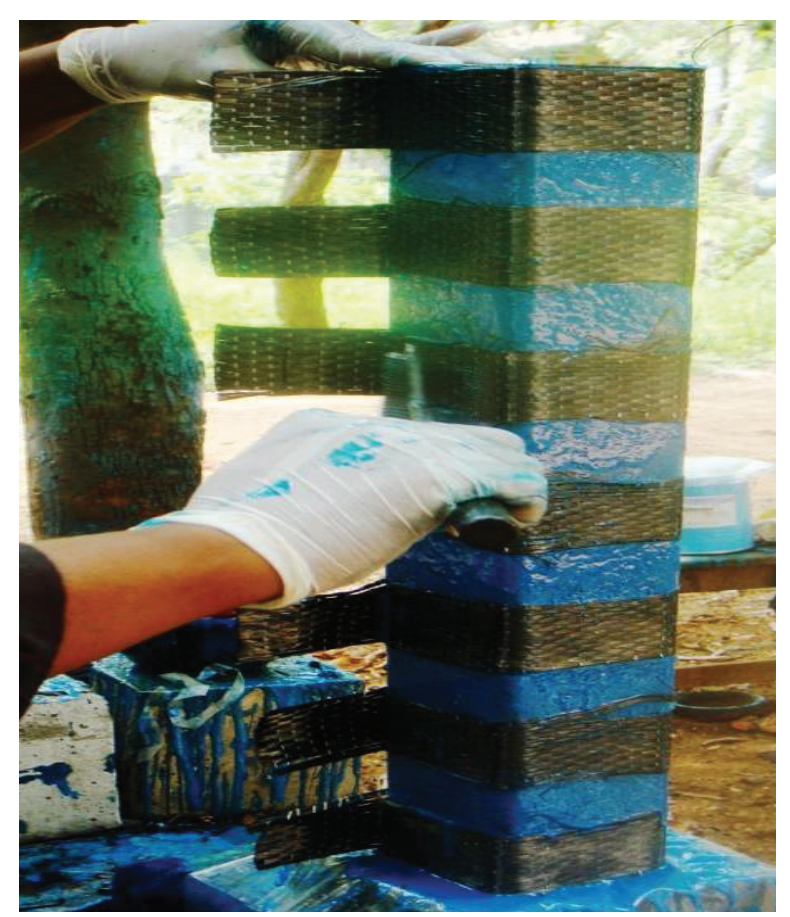

Fig. 4. Bonding of CFRP

\subsection{Experimental Setup}

The corroded HSS sections were tested in compression testing machine of capacity $2000 \mathrm{kN}$. Each member was positioned on the supports taking care to ensure that its centerline was exactly in line with the axis of the machine. The verticality of the specimens was checked using plumb bob and sprit level. The specimens were instrumented to measure longitudinal axial compression. The load was applied to the column by hydraulic jack and monitored by using $1000 \mathrm{kN}$ capacity load cell. Axial deformation 
of the column was measured by using linear voltage displacement transducer (LVDT) which was kept at top of the jack. The load cell and LVDT were connected with the 16-Channel Data Acquisition System to store the respective data. At the beginning, a small load of $20 \mathrm{kN}$ was applied slowly, so that the columns settle properly on its supports. Then the load was removed after checking the proper functioning of the instrumentation. The trial load was applied again slowly and the column was then tested to failure by applying the compressive load in small increments and the observations such as axial deformation and the ultimate load were carefully recorded. The load at which the CFRP starts rupturing and the nature of failure were also noted for each column. The experimental setup is shown in the Figure 5.

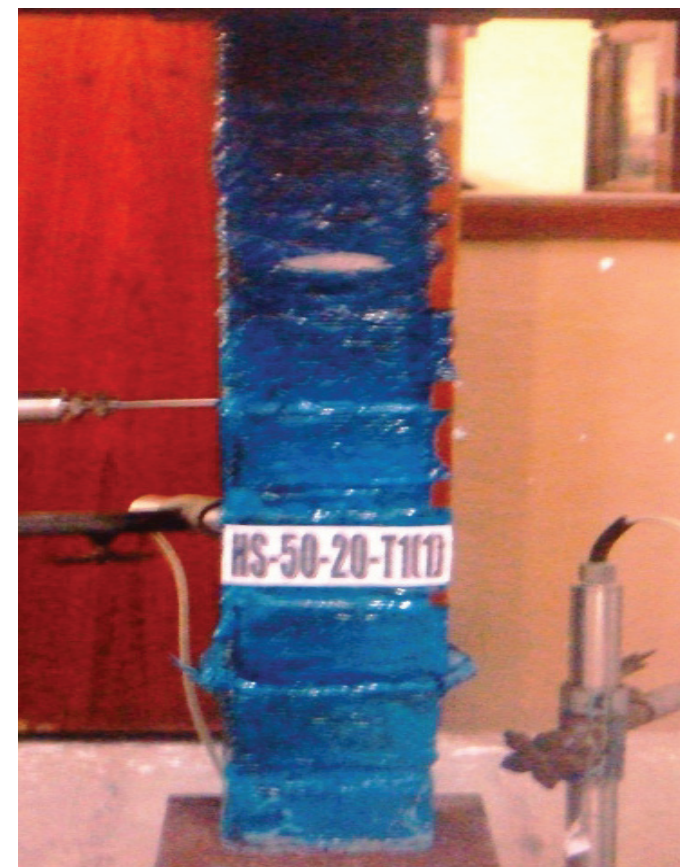

Fig. 5. Experimental Set up

\section{RESULTS AND DISCUSSIONS}

Among Fourteen specimens, six specimens were externally bonded by CFRP strips having a constant width of $50 \mathrm{~mm}$ wrapped with the spacing of $20 \mathrm{~mm}$ and remaining six specimens were externally bonded by CFRP strips having a constant width of $70 \mathrm{~mm}$ wrapped with the spacing of $20 \mathrm{~mm}$, two specimens were unbonded. All the specimens were tested until failure to understand the influence of FRP on axial behaviour of all strengthened specimens through the failure modes, axial stress-strain behaviour and ultimate load carrying capacity and they are described below. 


\subsection{FAILURE Modes}

The columns were subjected to axial load until failure to understand the influence of carbon fibre fabrics on the axial behavior of CFRP members. A linear response was observed in all unwrapped specimens up to the failure load and thereafter non-linear response was observed. And also, outward buckling at the top on all four sides of the steel tube was noted in the control specimens CC1, CC2 at the load of $546 \mathrm{kN}$ and 564 $\mathrm{kN}$ respectively which is shown in Figure 6. The failure of specimens [HS-50-20-T1(1) and HS-50-20-T1(2)] were occurred at the load of $709 \mathrm{kN}$ and $692 \mathrm{kN}$ respectively and, at the same time, the axial deformation of the specimens exceeded their permissible limit. The failure mode was rupture of fibre which was occurred at $160 \mathrm{~mm}$ from the bottom edge of the columns which is shown in Figure 7. From the above observations, it can be understood that a good composite action exist between the two components were confirmed. After rupture of CFRP, the load gets suddenly reduced. The abrupt reduction in load may be attributed to immediate absence of confinement provided by the CFRP and resulted in outward buckling of tubes. The similar failure mode was observed in the case of specimens strengthened with two layers of CFRP fabrics [HS-50-20-T2(1) and HS-50-20-T2(2)] and the rupture of fibre was occurred at $250 \mathrm{~mm}$ below the top of the column and shown in Figure 8.

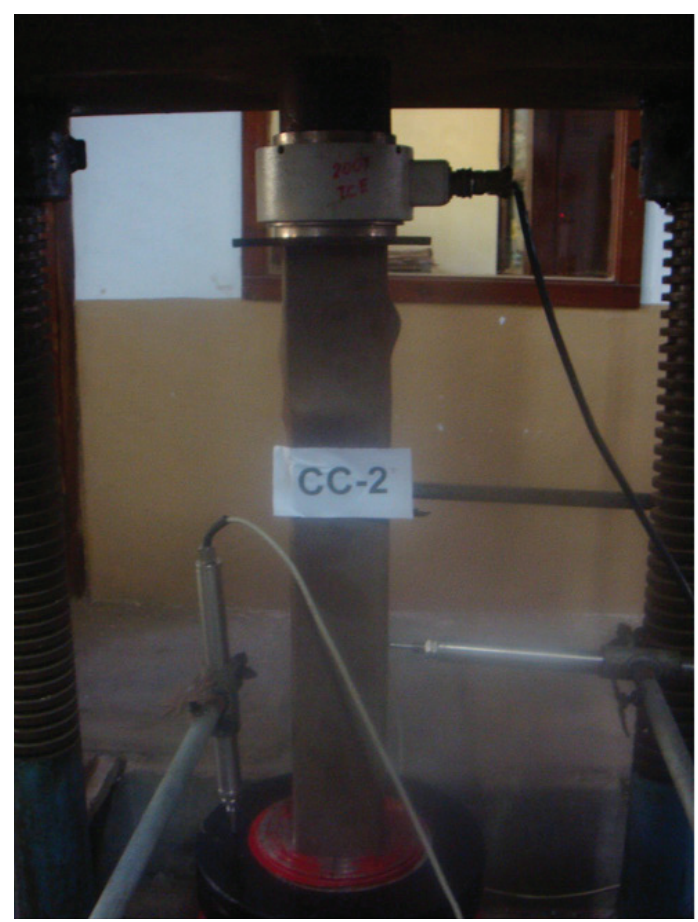

Fig. 6. Failure mode of column CC2 


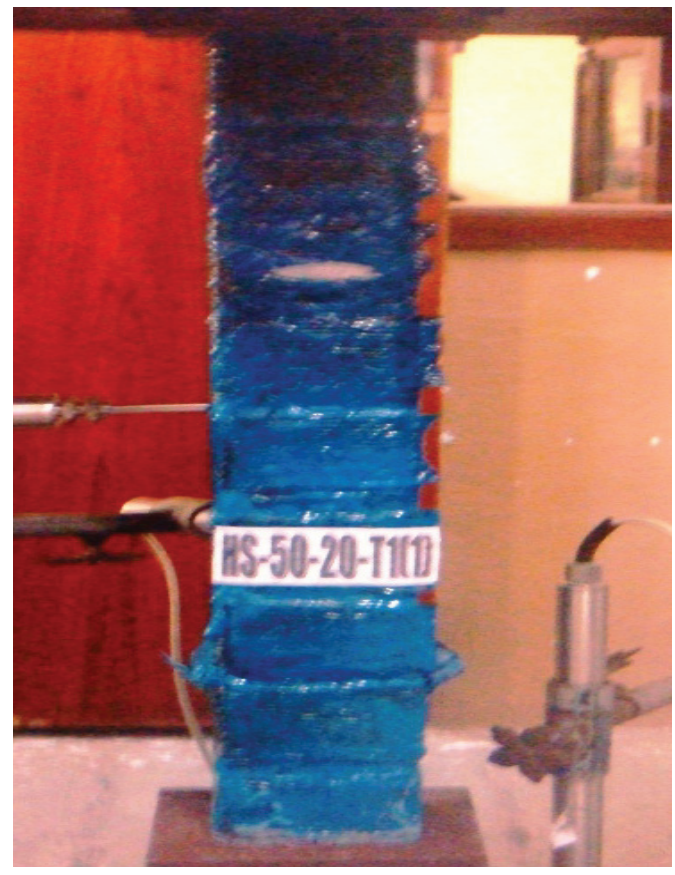

Fig. 7. Failure mode of column HS-50-20-T1(1)

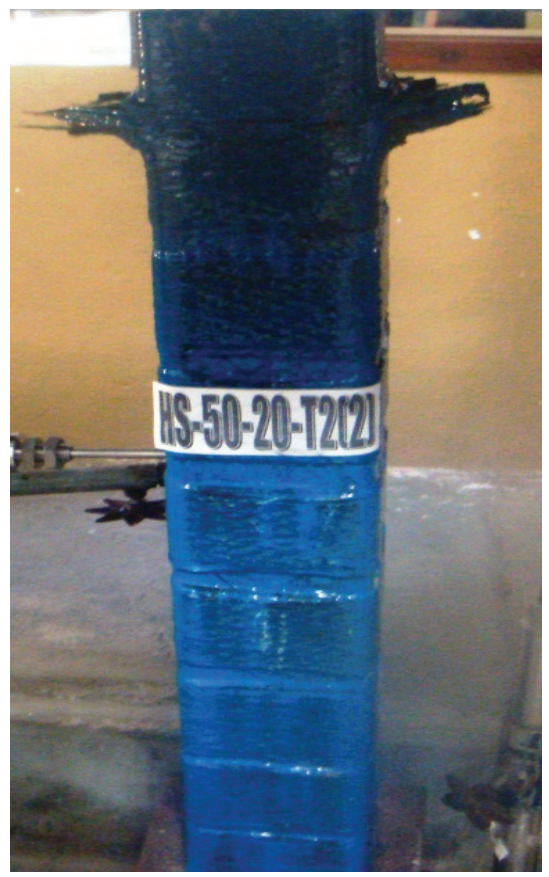

Fig. 8. Failure mode of column HS-50-20-T2(2)

The crushing of resin with the huge sound was observed in the case of columns HS-50-20-T3(1) and HS-50-20-T3(2) at the initial stage and they were exhibited linear elastic behavior until reaching a load of $1000 \mathrm{kN}$ on jack and thereafter non-linear response was observed and shown in Figure 9. When increasing the width of FRP strips from 50 to $70 \mathrm{~mm}$, the above similar behaviour was observed in those columns besides the buckling stresses of the columns were increased. The failure of specimens [HS-7020-T1(1) and HS-70-20-T1(2)] were occurred at the load of $731 \mathrm{kN}$ and $724 \mathrm{kN}$ respectively, the failure mode was rupture of fibre which was occurred at $180 \mathrm{~mm}$ from the bottom edge of the columns which is shown in Figure 10. The similar failure mode was observed in the case of specimens strengthened with two layers three layers of CFRP fabrics [HS-70-20-T2(1), HS-70-20-T2(2), HS-70-20-T3(2)and HS-70-20-T3(2) ] and the rupture of fibre was occurred at $280 \mathrm{~mm}$ below the top of the column and shown in Figs. 11 and 12. At the respective failure load of control column, no obvious changes in the above specimens were noticed and an axial deformation of $7.33 \mathrm{~mm}$ was observed. Among these, the specimens HS-70-20-T3 (1) and HS-70-20-T3(2) exhibited a sudden failure which result in rupture of CFRP jackets observed at the bottom of specimen once they reached their peak loads as shown in Figure 12. 


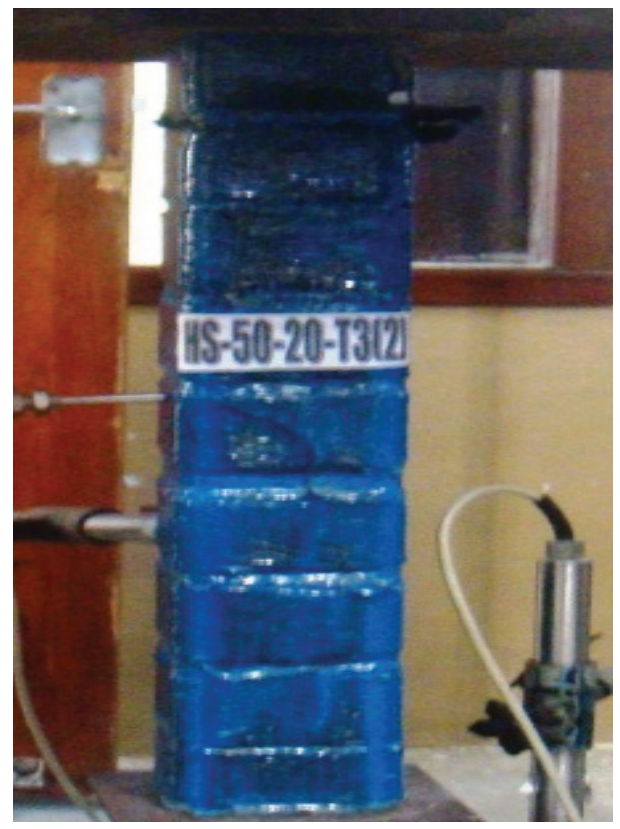

Fig. 9. Failure mode of column HS-50-20-T3(2)

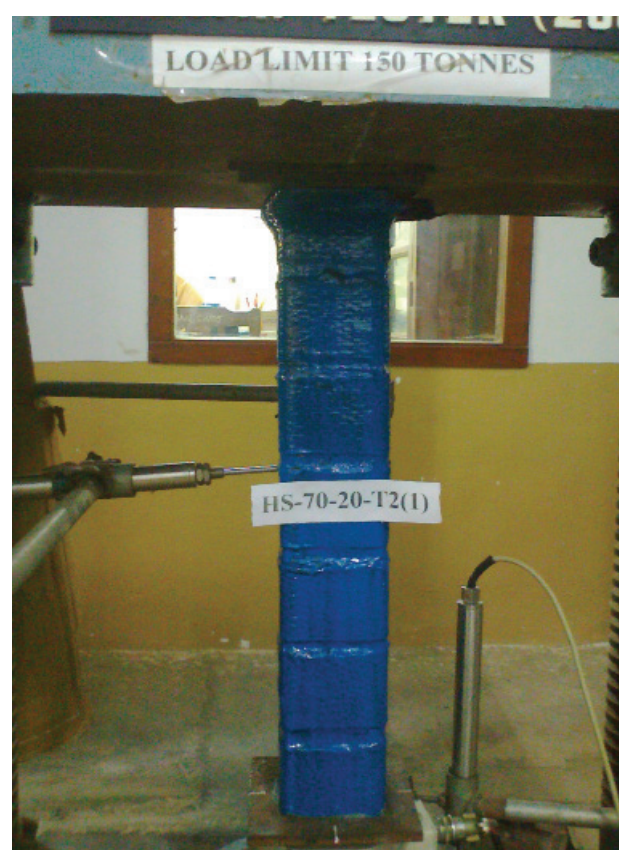

Fig. 11. Failure mode of column HS-70-20-T2(1)

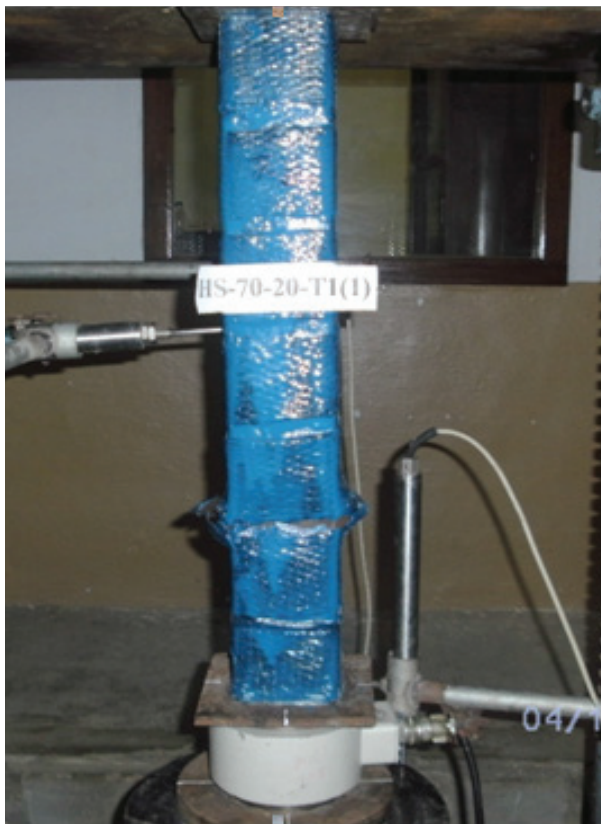

Fig. 10. Failure mode of column HS-70-20-T1(1)

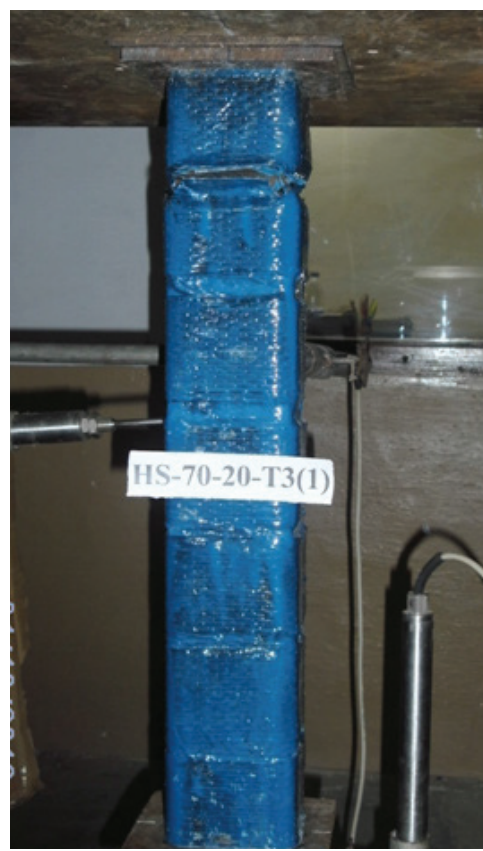

Fig. 12. Failure mode of column HS-70-20-T3(1) 


\subsection{Axial Stress-Strain Behaviour}

The test results such as maximum axial deformation and percentage of control in axial deformation of confined columns with respect to reference column were summarized in Table 4 and also presented in the graphical manner which is shown in Figure 13. From that, at the initial stage the control and CFRP confined columns exhibited linear elastic behavior followed by in-elastic response when increasing the load further. Furthermore, a significant fall in curve was observed at the peak stage due to sudden rupture of CFRP. And also, it was observed that the confined columns sustained higher ultimate load and larger axial deformation compared to control column.

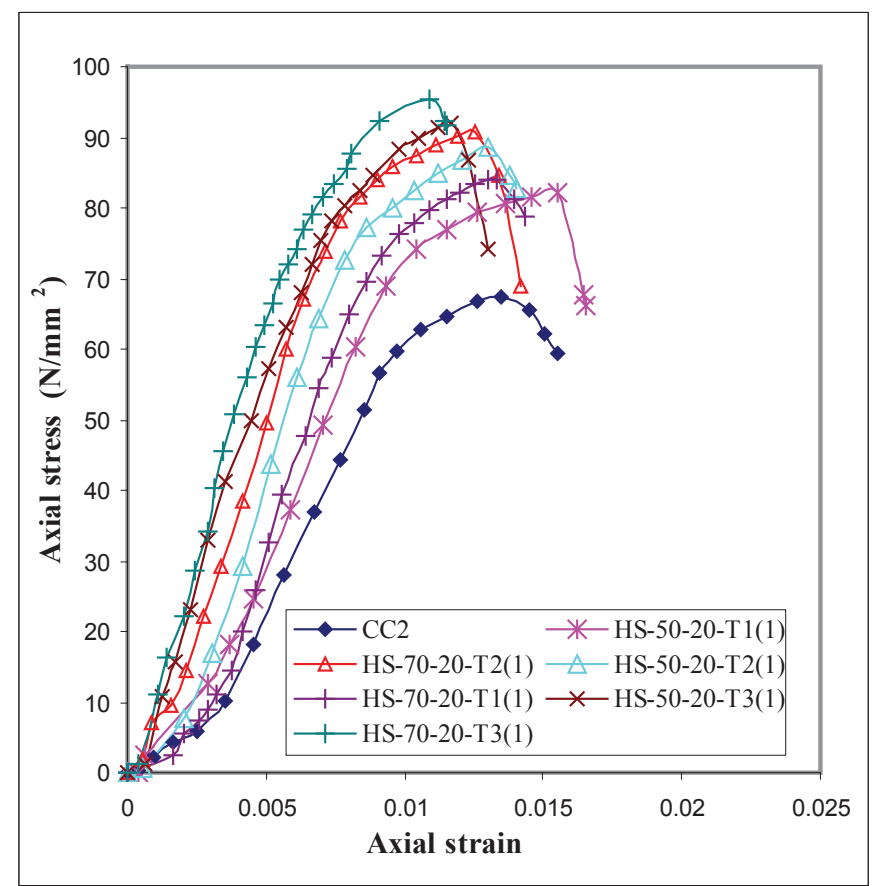

Fig. 13. Axial stress-strain behaviour - Comparison

\subsection{Ultimate Load Carrying Capacity}

Table 4 summarizes the maximum load carrying capacity and percentage increase in it of all CFRP strengthened columns compared with the control column. The main objective of this investigation is to enhance the axial strength of columns and also to advance the lateral confinement pressure by means of providing external CFRP strips in the form of horizontal lateral external ties. As expected, the external bonding of CFRP strips considerably enhance the load carrying capacity of the columns, especially the columns 
Table 4

Experimental result of all specimens

\begin{tabular}{|c|c|c|c|c|}
\hline S.No & $\begin{array}{c}\text { Designation of } \\
\text { columns }\end{array}$ & $\begin{array}{c}\text { Failure load } \\
\mathbf{( k N )}\end{array}$ & $\begin{array}{c}\text { Maximum axial } \\
\text { deformation } \\
\mathbf{( m m})\end{array}$ & $\begin{array}{c}\text { \% of increase in axial } \\
\text { load carrying capacity }\end{array}$ \\
\hline 1 & CC1 & 546 & 8.29 & -- \\
\hline 2 & CC2 & 564 & 8.35 & -- \\
\hline 3 & HS-50-20-T1(1) & 709 & 7.91 & 25.71 \\
\hline 4 & HS-50-20-T1(2) & 692 & 7.45 & 35.46 \\
\hline 5 & HS-50-20-T2(1) & 764 & 7.46 & 32.44 \\
\hline 6 & HS-50-20-T2(2) & 747 & 6.93 & 44.32 \\
\hline 7 & HS-50-20-T3(1) & 814 & 6.12 & 42.37 \\
\hline 8 & HS-50-20-T3(2) & 803 & 6.02 & 29.6 \\
\hline 9 & HS-70-20-T1(1) & 731 & 9.34 & 28.36 \\
\hline 10 & HS-70-20-T1(2) & 724 & 9.15 & 43.43 \\
\hline 11 & HS-70-20-T2(1) & 809 & 8.45 & 42.02 \\
\hline 12 & HS-70-20-T2(2) & 801 & 8.02 & 68.4 \\
\hline 13 & HS-70-20-T3(1) & 950 & 7.02 & 67.37 \\
\hline 14 & HS-70-20-T3(2) & 944 & 7.33 & \\
\hline
\end{tabular}

strengthened by three layers of CFRP strips were outperformed. Compared to control column, the enhancement in axial load carrying capacity of columns HS-50-20-T1(1), HS-50-20-T2(1) and HS-50-20-T3(1) was found as 25.71\%, 35.46\%, and 44.32\% more than that of control columns. In the meanwhile the load carrying capacity of HS-7020-T1(1), HS-70-20-T2(1) and HS-70-20-T3(1) was found as $29.6 \%, 43.43 \%$, and $68.4 \%$ more than that of columns wrapped with $50 \mathrm{~mm}$ spacings. From the above, it can be observed that, the increase in load carrying capacity can be occurred by increasing the area of CFRP composites.

\section{Conclusions}

Horizontal wrapping style of narrow strip of CFRP fabrics is proposed in this study for improving the confinement pressure of HSS tubular members externally. From the experimental data obtained, failure modes, axial load carrying capacity and the contribution of FRP fabrics on corroded HSS columns were discussed. Based on the compressive tests on fourteen specimens wrapped with CFRP strips with different spacing, the following conclusions can be made: 
- Outward buckling at the top on all four sides of the steel tube was observed in the case of control specimens $\mathrm{CC} 1$ and $\mathrm{CC} 2$.

- The corroded HSS columns confined by CFRP fabrics sustained higher ultimate load and larger axial deformation compared to control columns.

- The columns confined with three layers of CFRP strips tend to have more ability to control axial deformation compared to those columns confined by one and two layers of CFRP.

- The enhancement in load carrying capacity of columns with CFRP strips such as HS-50-20-T1(2), HS-50-20-T2(2) and HS-50-20-T3(1) compared to control column observed at the failure load of control specimen was $22.69 \%, 32.44 \%$ and $44.32 \%$ respectively whereas the load carrying capacity of HS-70-20-T1(1), HS-7020-T2(1) and HS-70- 20-T3(1) was found as $29.6 \%, 43.43 \%$, and $68.4 \%$ was more than that of columns wrapped with $50 \mathrm{~mm}$ spacing.

\section{REFERENCES}

1. Michael V. Seica and Jeffrey A. Packer: 'FRP materials for the rehabilitation of tubular steel structures, for underwater applications', Elsevier Composites Structs., 80, 440-450, 2007.

2. H. JIAO and XL. ZHAO: 'CFRP strengthened buttwelded very high strength (VHS) circular steel tubes', Thin-Walled Structures, 42, (7), 963-78, 2004.

3. A. Shatt and A. Fam: 'Axial loading tests on CFRPretrofitted short and long HSS steel columns', Canadian Jl. of Civil Engg. 33, (4), 458-70, 2006.

4. A. ShaAt and A. FAm: 'Modeling of axially loaded HSS slender steel columns strengthened with CFRP sheets', Intl. Conf. on Advances in Engg. Structs., Mech. and Construct., 2006.

5. YH. Zhaо, W. Gu, J. Xu and HT. Zhang: 'The strength of concrete-filled CFRP steel tubes under axial compression', ISOPE conference, JSC-313, 2005.

6. Z. TAO, LH. HAN and JP. ZhUANg: 'Experimental behavior of CFRP strengthened concrete-filled steel tubular stub columns', Advances in Structural Engineering, 2006.

7. J. Haedir, M.R. Bambach, XL. Zhao and RH. Grzebieta: 'Bending strength of CFRP-strengthened circular hollow steel sections', Third Intl. Conf. on FRP Composites in Civil Engg., 2006.

8. M.R. Bambach, H.H. Jama and M. Elchalakani: 'Effect of externally bonded CFRP on the local buckling and axial capacity of steel SHS', Fifth international conference on coupled instabilities in metal structures, Sydney, Australia, 23-25, 2008. 